NBER WORKING PAPER SERIES

\title{
A SIMPLE MODEL OF OPTIMAL HATE CRIME LEGISLATION
}

\author{
Li Gan \\ Roberton C. Williams III \\ Thomas Wiseman \\ Working Paper 10463 \\ http://www.nber.org/papers/w10463
}

\author{
NATIONAL BUREAU OF ECONOMIC RESEARCH \\ 1050 Massachusetts Avenue \\ Cambridge, MA 02138 \\ April 2004
}

The views expressed herein are those of the author(s) and not necessarily those of the National Bureau of Economic Research.

(C2004 by Li Gan, Roberton C. Williams III, and Thomas Wiseman. All rights reserved. Short sections of text, not to exceed two paragraphs, may be quoted without explicit permission provided that full credit, including (C) notice, is given to the source. 
A Simple Model of Optimal Hate Crime Legislation

Li Gan, Roberton C. Williams, and Thomas Wiseman

NBER Working Paper No. 10463

April 2004

JEL No. K14, K42, J71

\section{$\underline{\text { ABSTRACT }}$}

We present a simple model of the effects of hate crime legislation. It shows that even if the direct harm to victims of hate crime is the same as for other crimes, because of other differences in the effects it may still be optimal to exert more law-enforcement effort to deter or prevent hate crime. These differences also have previously unrecognized effects on the optimal level of effort by potential hate crime victims to avoid being victimized, thus affecting the efficiency of government policies that encourage or discourage such effort. We discuss the implications of these results for optimal hate-crime policy, as well as for policy toward other similar crimes, such as terrorism.

\section{Li Gan}

Department of Economics

University of Texas

Austin, TX 78712

and NBER

gan@eco.utexas.edu

Roberton C. Williams III

Department of Economics University of Texas

Austin, TX 78712

and NBER

rwilliam@eco.utexas.edu

Thomas Wiseman

Department of Economics

University of Texas

Austin, TX 78712

wiseman@eco.utexas.edu 


\section{Introduction}

Reported "hate crimes" have increased dramatically in the United States in recent years; the number of reported incidents rose from 4,588 in 1991 to 9,730 in $2001 .^{1}$ This rise, along with the attention paid by popular media to high profile cases, such as the murders of James Byrd in Texas and Matthew Shepard in Wyoming, has produced unprecedented public interest in the issue and potential remedies. As of 1999, 41 states had passed "hate crime" or "bias crime" laws: laws that create or enhance penalties for crimes motivated at least in part by the victim's race, religion, or other protected category (see Grattet and Jenness, 2001). ${ }^{2}$ In essence, these laws mandate stronger punishment based on the motivation behind the crime. Debate over these laws centers on the question of whether this additional punishment is justified. ${ }^{3}$

Hate crime has attracted substantial attention in the fields of law, sociology, psychology, and other social sciences, but very little within the field of economics. Jefferson and Pryor (1999), Medoff (1999), and Gale, Heath, and Ressler (2002) provide empirical analyses of hate crime data. The latter two papers also briefly present theories to explain hate crimes. Glaeser (2002) provides a much more extensive and thorough economic theory of hatred. None of these papers, however, address the normative issue of optimal hate crime policy.

In this paper, we present a formal model of law enforcement in the presence of hate crimes, and use that model to investigate the conditions under which it is optimal to impose harsher penalties for hate crimes-or, more generally, to exert greater public effort

\footnotetext{
${ }^{1}$ See Federal Bureau of Investigation (1991 and 2001). Of course, the rise could be due to increased reporting rather than higher rates of such crime, but in either case, it indicates increased attention to the problem.

${ }^{2}$ The set of protected categories varies across different states' laws; as of 1999, nearly all included race, religion, and national origin, while gender, sexual orientation, and disability were protected in roughly half of the states with hate crime laws. A handful of states also include such categories as political affiliation, age, marital status, involvement in civil rights, or service in the armed forces.

${ }^{3}$ Jacobs and Potter (1998, p. 147) articulate the argument against hate crime laws: "We do not believe that crimes motivated by hate invariably are morally worse or lead to more severe consequences for the victims than the same criminal act prompted by other motivations."
} 
to prevent hate crimes-than for otherwise similar crimes not motivated by hatred. We also examine the implications of these conditions for other aspects of hate crime policy: for example, should government policy encourage effort by members of targeted groups to make themselves less likely to be victims of hate crime?

Our model is similar in nature to Becker's (1968) economic model of crime. ${ }^{4}$ In this model, potential criminals derive some benefit from committing a crime, but weigh that against their expected cost-both in terms of effort and expected punishment-when deciding whether or not to commit a crime. Law enforcement and efforts by potential targets to protect themselves from crime can increase the expected cost to potential criminals, and thus reduce crime rates.

While there is widespread agreement on the defining characteristic that distinguishes hate crime from other crime-the motivation for the crime-there is much less agreement on the effects of hate crime and on exactly why such crimes should be punished more harshly. To accommodate this diversity of opinion, we consider five possible ways in which hate crimes may differ from other crimes and thus warrant greater punishment, drawing on hate crimes research from other social sciences and on Glaeser's (2002) economic theory of hatred,. First, society may put a lower weight on the utility of hate criminals than on the utility of other criminals. For example, the utility that a mugger gets from stolen money would count in calculating social welfare, but the pleasure that the perpetrator of a hate crime gets from inflicting suffering is invalid and should not be counted. ${ }^{5}$ Second, hate crime may harm other people in addition to the direct victim. In particular, other members of the targeted group may suffer disutility from sympathy for the victim or fear that they themselves will be attacked.

Third, efforts by potential targets to avoid being victims of hate crime may generate a negative externality. For example, they might try to hide their identities, thus

\footnotetext{
${ }^{4}$ Freeman (1999) provides a survey of the extensive literature related to the Becker model.

5 The phenomenon of "hating the haters" noted by Glaeser (2002) would also lead to a lower (or even negative) weight on the utility of hate criminals.
} 
resulting a loss of diversity to society. Fourth, hate crime might be more difficult for victims to avoid. A person can reduce his chance of being mugged by avoiding visible displays of wealth, but cannot change his skin color to avoid race-based hate crime. Fifth, there may be fewer potential targets of hate crime than for other crimes, leading to a higher probability that any particular potential target will in fact be a victim. While the primary focus of this paper is on hate crimes, it is worth noting that the first four of these differences also apply to acts of terrorism, and thus many of our conclusions will also apply to anti-terrorism policy as well.

We show that each of these differences may justify greater public effort to prevent hate crimes than to prevent other crimes, even if the direct harm to the victim is the same. However, in most of these cases, greater public effort is optimal only under particular conditions, most notably on the complementarity or substitutability between public and private effort-a point that prior hate crime research has not noted. ${ }^{6}$ We also show that these differences between hate crime and other crimes affect the socially optimal level of private effort relative to the individually optimal level. Thus, if the government can encourage or discourage private effort through means other than just the overall level of public effort-for example, if it is possible to subsidize private effort or to choose types of public effort that are more complementary to private effort-then it will be optimal for hate crime policy to differ from policy toward other crimes on those dimensions as well as on the overall level of public effort.

In the next section, we present a simple model that incorporates these differences and demonstrates their implications for the optimal design of hate crime legislation. The final section contains conclusions and a discussion of additional factors that fall outside the scope of the model.

\footnotetext{
${ }^{6}$ Many studies in law and economics have shown that the optimal level of government effort to prevent crime depends strongly on the degree of complementarity or substitutability between government and private effort (see, e.g., Ben-Shahar and Harel, 1995). Some of our results are similar to the results of those studies in that they stem from distortions in potential victims' decisions about how much effort to exert to avoid being victimized. However, the sources of those distortions in this paper are quite different from those in prior work.
} 


\section{The Model}

In this section, we first provide a baseline model of crime and law enforcement that applies to any crime, and then extend that model to capture the ways in which hate crime may differ from other crimes.

\section{A. The Baseline Model}

Three types of agents interact with each other: potential criminals, potential victims, and the government. There is a continuum of mass $N^{C}$ of potential criminals. Each criminal $i$ chooses to commit one crime if the benefit $B_{i}$ from doing so exceeds the expected cost $C^{C}$. The benefit from crime for each criminal is drawn independently from a uniform distribution on the interval $[0,1]$. The cost of committing a crime is given by the average protection level (defined below) across potential victims, $\bar{P}$, and is the same for all potential criminals. ${ }^{7}$ The mass of crimes committed, then, is $N^{C}[1-\bar{P}]$.

The group of potential victims constitutes a continuum of mass $N^{V}>N^{C}$. All potential victims are assumed to be identical. If a crime is committed against a particular potential victim, that victim suffers a utility loss of $\Delta U \in(0,1)$. The protection level for potential victim $i, P\left(a_{i}, g\right)$, is a function both of individual effort to avoid crime $\left(a_{i}\right)$ and of the level of government effort to catch and punish criminals $(g)$. The function $P$ is assumed to be bounded between 0 and 1, and to be increasing and strictly concave in each of its arguments: $P_{1}>0, P_{2}>0, P_{11}<0$, and $P_{22}<0$. That is, exerting more effort of either type raises the level of protection, but the marginal effect falls as the level of effort rises. For now, we make no assumptions on the degree of complementarity or substitutability between individual and government effort (that is, on the sign and magnitude of the cross-partial derivative $P_{12}$ ). As shown later in this paper, this parameter has important implications for hate crime policy. For simplicity, we assume that all third- and higher-order derivatives of $P$ are zero.

\footnotetext{
${ }^{7}$ For simplicity, we assume that there is no uncertainty in the cost of committing a crime. This should not affect the results, because this certain cost could represent the certainty equivalent of an uncertain cost.
} 
We assume that the cost of individual effort $C^{V}\left(a_{i}\right)$ increases quadratically. That is, $C_{1}^{V}>0, C_{11}^{V}>0$, and all higher order derivatives are zero. The probability that individual $i$ is victimized depends on his protection level $P\left(a_{i}, g\right)$ and on the ratio of the mass of potential criminals to the mass of potential victims $N^{C} / N^{V}$. In particular, we assume that the probability is given by $\frac{N^{C}[1-P(a, g)]}{N^{V}}$. The total number of crimes committed, then, is given by $N^{C}[1-P]$, as specified before.

Given government effort $g$, each potential victim maximizes expected utility by solving the problem

$$
\max _{a}\left\{(-\Delta U) \frac{N^{C}[1-P(a, g)]}{N^{V}}-C^{V}(a)\right\} .
$$

We assume that $C_{1}^{V}(0)$ is sufficiently small to ensure an interior solution to Expression (1). The necessary and sufficient condition for this unique solution $a^{*}$ is given by

$$
\Delta U \frac{N^{C}}{N^{V}} P_{1}\left(a^{*}, g\right)-C_{1}^{V}\left(a^{*}\right)=0 .
$$

Each individual chooses the same level of effort $a(g)$, which varies with government effort $g$, so the average protection level is equal to $P(a(g), g)$.. Implicit differentiation of Condition (2) yields the derivative

$$
a_{1}(g)=\frac{P_{12}(a(g), g) \frac{N^{C}}{N^{V}} \Delta U}{C_{11}^{V}(a(g))-P_{11}(a(g), g) \frac{N^{C}}{N^{V}} \Delta U} .
$$

Because the denominator of Expression (3) is positive, the sign of $a_{1}(g)$ is the same as the sign of the cross-partial derivative $P_{12}$. If individual and government efforts are complementary $\left(P_{12}>0\right)$, then the optimal level of individual effort increases with the level of government effort. If, on the other hand, government effort acts as a substitute for individual effort $\left(P_{12}<0\right)$, then individuals exert less effort as government effort rises.

The total effect of a marginal increase in government effort $(g)$ on the average protection level is $P_{2}(a(g), g)+a_{1}(g) P_{1}(a(g), g)$. Note that if individual and government effort are strong enough substitutes (that is, if $a_{1}(g)$ is negative enough), then 
increasing $g$ may actually lower the average protection level and result in more crime. However, we rule out that case as unrealistic.

The third and last type of agent is the government. The government faces a cost of effort in catching and punishing criminals (which we sometimes refer to just as punishment effort) given by the increasing and convex function $C^{G}(g)$. (We assume that the government's cost depends neither on the mass of crimes committed nor on the size of the group of potential victims. In Section III, we discuss the effects of relaxing that restriction.) The government chooses its effort level to maximize expected societal utility, which is the sum of potential victims' and criminals' utility, less the cost of government effort. ${ }^{8}$ Thus, the government's problem is given by

$$
\max _{g}\left[N^{V}\left\{(-\Delta U) \frac{N^{C}[1-P(a(g), g)]}{N^{V}}-C^{V}(a(g))\right\}+N^{C}\left\{\int_{P(a(g), g)}^{1}[B-P(a(g), g)] d B\right\}-C^{G}(g)\right] .
$$

In selecting its effort level $g$, the government must weigh the benefits of increasing $g$ against the costs. A higher government effort level $g$ affects the welfare of the potential victims in two ways. First, there is the direct effect of a lower crime rate resulting from the increased cost of committing a crime $P(a(g), g)$. Second, increasing $g$ changes the equilibrium level of avoidance effort by the victims $a(g)$, and thus leads to a different cost of effort $C^{V}(a(g))$. That second effect may be either a cost (if $a$ and $g$ are complements) or a benefit (if they are substitutes). On the other hand, the social cost of raising government effort $g$ includes both the direct cost to the government $C^{G}(g)$ and the cost to potential criminals due to the higher cost of committing crimes. The first order condition for an interior solution to the government's problem is given by

$$
\begin{aligned}
& N^{C} \cdot \Delta U\left[P_{1}(a(g), g) a_{1}(g)+P_{2}(a(g), g)\right]-N^{V} a_{1}(g) C_{1}^{V}(a(g)) \\
& +\left[P_{1}(a(g), g) a_{1}(g)+P_{2}(a(g), g)\right] \cdot[-1+P(a(g), g)] \\
& -C_{1}^{G}(g)=0 .
\end{aligned}
$$

\footnotetext{
${ }^{8}$ Glaeser and Sacerdote (2003) find that patterns of homicide sentencing are inconsistent with the predictions of this type of optimal law-enforcement model, and posit that this is caused by a taste for vengeance. Our analysis is primarily normative, and thus we ignore such issues, but they could be important in a positive analysis.
} 
Substituting in the first-order condition for potential victims (Expression (2)) and suppressing the arguments for the sake of clarity yields Condition (5a):

$$
N^{C} P_{2}\{\Delta U-1+P\}+N^{C} a_{1} P\{-1+P\}-C_{1}^{G}=0 .
$$

We assume that the cost function $C^{G}(g)$ is sufficiently convex that the government's objective function (in Expression (4)) is concave. In that case, Condition 5a is both necessary and sufficient for an interior solution to the government's optimization.

Finally, it is useful to consider the socially optimal level of avoidance effort by potential victims, because it will help in interpreting later results. Furthermore, while in this model the government can affect the level of avoidance effort only by changing the level of punishment effort, in a richer model, the government might have more influence. For example, the government might be able to tax or subsidize some types of avoidance activities, or might choose among different methods of law enforcement that vary in their degree of complementarity or substitutability with avoidance effort by potential victims. The socially optimal level of private effort $a^{* *}$ is the level that maximizes social utility (from Expression (4)). The first-order condition is given by

$$
N^{C} P_{1}\left(a^{* *}, g\right)\left\{\Delta U-1+P\left(a^{* *}, g\right)\right\}-N^{V} C_{1}^{V}\left(a^{* *}\right)=0,
$$

The notation $a^{* *}$ is used to distinguish the socially optimal level from the level that is optimal from the perspective of a potential victim,. $a^{*}$. Note that $a^{* *}<a^{*}:$ that is, the level of avoidance effort chosen by potential victims exceeds the socially optimal level. This occurs because potential victims do not take into account the utility of potential criminals, who are made worse off by greater avoidance effort. ${ }^{9}$

Absent any cost of effort by the government and potential victims, the optimal level of crime would equate the marginal $\operatorname{cost}\left(\Delta U \times N^{C}\right)$ to the victims of the additional

\footnotetext{
${ }^{9}$ Note that this effect could be reversed if there is a positive externality from avoidance effort-if, for example, avoidance effort by one potential victim also benefits other potential victims. Ayres and Levitt (1998) note that the Lojack system to prevent car theft has just such a positive externality. This system sends a radio signal to help police track a stolen car. Since the radio transmitter on the car is difficult for prospective thieves to discover, the presence of Lojack on some cars reduces car thefts even for cars without the system. In contrast, a highly visible alarm system might encourage a potential thief to steal a different car, thus creating a negative externality. For simplicity, we rule out such externalities from avoidance effort in this baseline model.
} 
crime resulting from lowering the expected cost $P$ to the benefit $\left(1 \times N^{C}[1-P]\right)$ that the mass of criminals committing crimes get from the lower cost. That is, the optimal expected cost $P$ would satisfy $\Delta U-1+P=0$. Because the value of $\Delta U$ lies between 0 and 1 , that optimal $P$ is also between 0 and 1 . When government and victim costs are included, we make two assumptions on the optimal level of government effort $g^{*}$. First, we assume that $g^{*}$ is strictly positive, so that the unique solution is characterized by Condition (5a). That is, there is scope for government action after the private effort by the potential victims is undertaken. Second, we assume that $g^{*}$ is such that $\Delta U-1+P\left(a\left(g^{*}\right), g^{*}\right)>0$. That is, the equilibrium level of crime at the optimum level of government effort is higher if effort is costly than if effort is costless. By making those two assumptions, we restrict attention to what we consider the interesting, realistic case.

\section{B. Hate Crimes}

We consider five possible ways in which hate crime might differ from other crime in the context of our model, each of which could imply a higher optimal level of government effort to prevent hate crime than to prevent other crimes. In each case, we hold the rest of the model fixed.

The first is that the utility of those who commit hate crimes might get a lower weight in the government's objective function than the utility of those who commit other crimes. One argument that would support this approach is that some sources of utility should not count toward social welfare. As stated by a survey respondent cited in Iganski (2001, p. 632), “it is somehow more odious to harm someone for no other reason than because of who they are, not because they have something that you want." Thus, while the utility that a mugger gets from the money that he steals would count, the utility that the perpetrator of a hate crime gets from inflicting suffering would not count.

Glaeser's (2002) theory of hatred provides an alternative argument. He notes that one effective strategy for fighting hatred is to publicize images of violent hate-motivated attacks on minorities, which leads people to "hate the haters." In this case, those who 
hate the haters would derive utility from making potential hate criminals worse off, which would reduce the weight on the potential criminals' utility (or even lead to a negative weight, for a sufficiently large number of people with a sufficiently strong level of hate against the haters). Under either argument, the relative weight on criminals utility would be lower. We model this by multiplying the term for the criminals' utility $\left(N^{C}\left[\int_{P}^{1} B-P\right]\right)$ in the government's objective function in Expression (4) by the parameter $\delta$, where $\delta<1$ and represents the relative weight on criminals' utility.

Second, hate crime might generate a negative externality. This could occur in several ways. Members of the targeted group other than the direct victim may also suffer disutility from the crime, because they feel threatened or feel sympathy for the victim. A report by the U.S. Department of Justice (1997, p. x) says that "A hate crime victimizes not only the immediate target but every member of the group that the immediate target represents." Other members of society may feel ashamed that such crimes took place. Hate crimes may incite retaliatory attacks by members of the targeted group, making the victims of those attacks worse off. The Department of Justice report goes on to note that "Apart from their psychological impacts, violent hate crimes can create tides of retaliation and counterretaliation." Recall that the number of crimes is $\left(N^{C}[1-P(a(g), g)]\right)$. We model the negative externality by adding the term $f\left(N^{C}[1-P(a(g), g)]\right)$ to the government's objective function in Expression (4), where $f\left(\_\right.$) is a negative and decreasing function. ${ }^{10}$

Third, avoidance effort by potential victims may generate a negative externality. One way to avoid being a victim of hate crime is to hide your identity: Jews may try to pass as non-Jews, or gays may remain closeted, for example. If society values diversity, efforts like this to hide one's identity will create a negative externality. ${ }^{11}$ These efforts

\footnotetext{
${ }^{10}$ On the other hand, widespread hatred of the targeted group would imply a positive externality from hate crime, because other people who share the perpetrator's hatred will also derive utility from the harm he inflicts on the victim. This could lead to a lower optimal penalty or even a reward for crimes against a sufficiently hated minority-a very troubling conclusion.

${ }^{11}$ However, this could also create a positive externality if visible minorities generate disutility-again, a troubling conclusion. For example, those who are homophobic may prefer to have gays be forced to stay
} 
may also increase hatred. In Glaeser's (2002) model, contact with members of a minority group makes it more costly to hate that group, and thus reduces the level of hatred. But that effect could be reduced or eliminated if minority individuals hide their identities or avoid contact with those who hate them. ${ }^{12}$ And hate crimes often target those who are fighting for minority rights (e.g., civil rights workers and politically active blacks in the American South during the 1960's). We model these cases by adding the term $e(a(g))$ to the government's objective function in Expression (4), where $e(\perp)$ is a negative and decreasing function that represents this negative externality.

Fourth, it may be more difficult to avoid being the victim of a hate crime than to avoid being the victim of other crimes. McDevitt et al. (2001, p. 706) says that unlike victims of other crimes, “...bias crime victims expressed feelings of frustration when asked how to prevent or reduce such crimes in the future. They generally did not indicate that their actions had done anything to provoke or exacerbate a situation." It is relatively easy to avoid visible displays of wealth and thus reduce one's chances of being mugged, but it is impossible to change one's skin color to avoid race-based hate crime, for example. We model this as a uniform increase in the marginal cost of avoidance effort by potential victims, $C_{1}^{V}$, to $C_{1}^{V}+\varepsilon$. The second derivative, $C_{11}^{V}$, is unchanged.

Fifth, since hate crimes typically target minorities, the number of potential victims may be smaller for a hate crime than for other crimes, thus raising the probability that any particular individual in that group will be a crime victim. We model this by having a smaller mass of potential victims $N^{V}$.

Note that we do not explicitly consider the case in which the direct harm to the victim $(\Delta U)$ differs between hate crimes and other crimes. The implications of that case are obvious: if hate crime does more harm to the victim than other crime, then, all else the

in the closet. This, along with the argument in the previous footnote, may explain why support is much weaker for hate crime laws that include sexual orientation among the protected categories than for those that do not (see Johnson and Byers, 2003).

${ }^{12}$ McDevitt et al. (2002) find that roughly $25 \%$ of hate crimes reported in Boston targeted minority households that had recently moved into a previously all-White block, with the apparent goal of convincing the outsider to move to a different neighborhood. 
same, this will imply a higher optimal punishment.

\section{Results}

Here we analyze the optimal government effort to catch and punish criminals ( $g$ ) for each of the five potential differences between hate crime and other crimes, as described in the previous section. We show that in either of the first two cases (discounting criminals' utility, negative externality from crime), the optimal punishment effort is higher for a hate crime than for other crime, all else equal. For the other three cases, the effect depends on the degree of complementarity or substitutability between victim and government effort. In the third or fifth case (negative externality from avoidance effort, smaller mass of potential victims), optimal government effort is higher for a hate crime if individual and government effort are substitutes, but lower if they are complements. In the fourth case (higher marginal cost of avoidance effort), optimal government effort is higher for hate crime if individual and government effort are sufficiently strong substitutes. If they are complements or are sufficiently weak substitutes, the optimal government effort will be lower for hate crime than for other crime.

Formally, let $g^{*}$ denote the optimal government effort in the baseline model, and let $g^{H 1}, g^{H 2}, g^{H 3}, g^{H 4}$, and $g^{H 5}$, respectively, denote the optimal levels for the five ways in which hate crime may differ from other crimes, taken one at a time. Our first result pertains to the first case, in which there is a lower weight in the government's objective function on the utility of potential hate criminals. One of the social costs of higher government effort is that it lowers the utility of potential criminals. If their utility gets a lower weight, that effectively lowers the social cost of government effort, and thus increases the optimal level of government effort.

Result 1. All else equal, if the utility of potential hate criminals gets a lower weight in the government's objective function than the utility of other potential criminals, the optimal punishment effort is higher for hate crime than for other crimes. 
Proof: In the baseline model, Condition (5a) is satisfied at $g^{*}$. Discounting the criminals' utility, $N^{C}\left[\int_{P(a(g), g)}^{1} B-P(a(g), g)\right]$, in the government's objective function in Expression (4) by multiplying it by $\delta$ means that the term $\left.N^{C}\left[P_{1} a_{1}+P_{2}\right]-1+P\right\}$ will be multiplied by $\delta$ in the derivative in Condition (5). That term is strictly negative, as long as public and private effort are not such strong substitutes that higher public effort reduces private effort by enough to increase the crime rate, which seems unrealistic. Thus, multiplying that term by $\delta$ (which is less than 1) drives the value of the expression above zero. Because the objective function is concave, then, $g^{H I}$ must exceed $g^{*}$ to restore optimality.

For the case in which there is a negative externality from hate crime, the benefit of reducing crime is greater, because less crime implies both less harm to victims and less harm from the externality. Thus, the optimal level of government effort is higher.

Result 2. All else equal, if there is a negative externality from hate crime, the optimal level of punishment effort is higher for hate crime than for other crimes.

Proof: Adding a negative externality $f\left(N^{C}[1-P(a(g), g)]\right)$ to the government's objective function in Expression (4) means adding the term $-f_{1}\left(N^{C}[1-P]\right)\left(P_{1} a_{1}+P_{2}\right)$ to the derivative on the left-hand-side of Condition (5a). That term is positive (again, as long as an increase in $g$ leads to a decrease in crime). So, as in the previous proof, $g^{H 2}$ must be greater than $g^{*}$ for the government's first-order condition to be satisfied.

Note that in both of these first two cases, the effect is different from that of simply increasing the harm to victims $(\Delta U)$. In the baseline model, potential victims choose a level of avoidance effort $\left(a^{*}\right)$ that exceeds the socially optimal level $\left(a^{* *}\right)$, because they do not take into account the effect on potential criminals' utility. The individually optimal level of effort would continue to exceed the socially optimal level if the harm to 
victims were increased, because the harm to victims appears in both the government objective function and the objective function for a potential victim. But lowering the weight on potential criminals' utility or introducing a negative externality from crime could change this result, because these terms do not appear in potential victims' objective functions; if these effects are sufficiently large, they would result in a socially optimal level of avoidance effort equal to or greater than the level that potential victims choose. In essence, the effect on potential criminals is a negative externality from potential victims' effort. Reducing the weight on potential criminals' utility reduces the magnitude of this externality, while introducing a negative externality from crime means that there is effectively a positive externality from avoidance effort, because it reduces crime; in either case, the socially optimal level of avoidance effort increases.

This has two implications for government policy toward hate crime. First, it affects the optimal level of punishment effort. In either of these first two cases, if public and private effort are substitutes then the increase in the optimal level of punishment effort will be smaller than it would be for an equivalent increase in the harm to victims: there is less incentive for the government to discourage private effort by increasing public effort. Conversely, if public and private effort are complements, then the optimal level of punishment effort will increase by more in either of these first two cases than for an equivalent increase in the harm to victims. In these cases, it is optimal for the government to do more to encourage (or do less to discourage) avoidance effort, and one way to do that is to adjust the level of punishment effort. In the extreme case in which avoidance and punishment effort are such strong substitutes that the equilibrium level of crime actually rises when punishment effort increases, this can reverse the effect on optimal punishment effort, which would fall. In contrast, simply increasing the damage to victims will always increase optimal punishment effort, regardless of the degree of substitutability between punishment and avoidance.

Second, this implies that if the government has other means to affect avoidance effort, the optimal policy for hate crimes would do more to encourage avoidance than 
would the optimal policy for other crimes. Thus, the government might subsidize avoidance effort for hate crimes, or might choose a method of enforcement and punishment that is more complementary to avoidance effort. These policies are beyond the scope of our model, but might well be important in a real-world setting. This is an issue that has gone largely unnoticed in both the public and academic debates over hate crime laws; the debate has focused primarily on enforcement and punishment effort, with little or no discussion of ways to encourage individuals to do more to protect themselves against hate crime. But, at least in these first two cases, any time it is optimal to exert more public effort to deter and punish hate crime, it is also optimal to encourage potential victims to exert more private effort.

Next, consider the third possible difference between hate crime and other crimes: there may be a negative externality from avoidance effort. In this case, the effect on optimal punishment effort is slightly more complicated. Recall that if government and individual effort are substitutes $\left(P_{12}<0\right)$, then the equilibrium level of individual effort $a(g)$ decreases with $g$. In that case, the externality increases the marginal benefit of government effort, since a higher $g$ leads to lower victims' effort. On the other hand, if $P_{12}>0$, then $a_{1}(g)>0$, and the externality decreases the marginal benefit of government effort. Thus, a hate crime under in this case requires a higher level of punishment effort in the case of substitutes, and a lower effort in the case of complements. That result is formalized below.

Result 3. All else equal, if there is a negative externality from hate crime avoidance effort, then the optimal punishment effort will be higher for hate crime than for other crime if punishment effort and avoidance effort are substitutes, and will be lower if they are complements.

Proof: Adding a negative externality $e(a(g))$ to the government's objective function in Expression (4) means adding the term $e_{1}(a(g)) a_{1}(g)$ to the derivative on the left-hand-side 
of Condition (5). According to Expression (3), if $P_{12}<0$, then so is $a_{1}(g)$, and the new term is positive. As before, then, $g^{H 2}$ must be greater than $g^{*}$ to restore equality. Analogously, if $P_{12}>0$, then the new term is negative, and $g^{H 2}$ is less than $g^{*}$.

Note that this leads to the opposite effect on the socially optimal level of avoidance effort from the first two cases: it is even further below the level that potential victims choose than it is in the baseline model. Thus, it is optimal for the government to do more to discourage avoidance effort, either through changing the level of punishment effort or through other means. This suggests that some hate crimes warrant more punishment effort than others; for example, if there is a negative externality from segregation, it might be optimal to have a harsher penalty for a hate crime committed against a black family living in an otherwise all-White neighborhood than for an otherwise identical hate crime committed against a black family living in a black neighborhood, in order to provide better incentives for integrating neighborhoods.

Now consider the fourth possible difference between hate crimes and other crimes: hate crimes are associated with a higher marginal cost of avoidance effort by potential victims. In that case, each government effort level $g$ is associated with a lower effort level and a higher marginal cost of effort in equilibrium for a hate crime relative to a regular crime. Suppose that $P_{12}>0$, so that victim and government effort are complementary, implying that $a(g)$ increases with $g$. Then a hate crime has three effects, all of which act to lower the optimal government effort. First, the marginal cost of individual effort (which is increasing in $g$ ) is higher. Second, the total marginal effect of $g$ on the protection level $P, P_{1} a_{1}+P_{2}$ falls. Finally, a lower level of victim effort means a greater mass of criminals committing crimes. Thus, the societal cost of increasing $P$ (the expected cost of committing a crime) increases, because there are more criminals incurring that cost. If $P_{12}$ $>0$, then, $g^{H 4}<g^{*}$.

When individual and government effort are substitutes $\left(P_{12}<0\right)$, two of the three effects change sign. Individual effort $a(g)$ now is decreasing in $g$, so the higher marginal 
cost of individual effort makes government effort more attractive. Similarly, the overall marginal effect of $g$ on $P$ rises with the fall in $a$. On the other hand, there is still a greater mass of active criminals, which reduces the welfare gain from raising $g$. If the degree of

substitutability is high enough, then the first two effects outweigh the third, and $g^{H 4}>g^{*}$. Those two findings are shown in Result 4.

Result 4. All else equal, if avoidance effort is more expensive for hate crimes than for other crimes, the optimal level of punishment effort is lower for hate crimes than for other crimes unless punishment and avoidance effort are sufficiently strong substitutes.

\section{Proof: see Appendix}

Effort to avoid crime and effort to catch and punish criminals might be strongly complementary if, for example, avoidance effort took the form of increased alertness and watchfulness for suspicious activity. In that case, the higher probability of witnesses would greatly increase the effectiveness both of police effort to catch criminals and of prosecutorial effort to convict them. On the other hand, if potential victims seek to avoid crime by secluding themselves at home, increased avoidance effort might hinder government effort to catch and punish criminals, and so there would be no complementarity.

Finally, consider the fifth way in which hate crime may differ from other crimes: the mass of potential victims $N^{V}$ is smaller. That change does not directly affect the number of crimes committed, which depends only on the mass of criminals $N^{C}$ and the average protection level. Instead, the change works indirectly through its effect on $a_{1}(g)$, the response of individual effort to a change in government effort. When $N^{V}$ rises, that derivative (and thus the total marginal effect of $g$ on $P$ ) increases if individual and government action are substitutes, and decreases if they are complements. There is also a second effect of a change in $N^{V}$ : the more victims that are incurring the cost of individual effort, the more desirable it is to decrease the equilibrium level of such effort. That is, 
increasing $g$ becomes more attractive in the case of substitutes, and less attractive in the case of complements. Both effects imply a higher level of government action if it is a substitute for effort by the victims, and a lower level if it is a complement, as Result 5 shows.

Result 5. All else equal, if there are fewer potential hate crime victims than potential victims of other crimes, the optimal punishment effort is higher for hate crimes than for other crimes when punishment and avoidance effort are substitutes, and lower when they are complements.

\section{Proof: see Appendix}

Note that we have assumed that the cost of government effort does not depend on

the volume of crimes committed $N^{C}[1-P]$, nor does it depend on the number of potential victims $N^{V}$. The consequence of relaxing that assumption and supposing instead that government costs increase with the volume of crime is to raise the optimal level of government effort $g$ both in the baseline model and for each definition of hate crime. There are no qualitative effects on any of our results, however. If we allow the cost of government effort to rise with the mass of the potential victims, there is a qualitative change only for this last case, in which there is a smaller pool of potential hate crime victims than of potential victims of other crimes. In this case, having the cost of government effort depend on the number of victims implies a lower cost of effort to prevent hate crimes, and thus a higher optimal level of government effort.

\section{Conclusion}

We have presented a simple model of the effects of hate crime legislation. It shows that even if the harm to the direct victim of hate crime is the same as the harm from non-hate-motivated crime, other differences may lead to a higher optimal punishment for hate crime. However, the implications of these other differences are not as 
straightforward as prior hate-crime research has implied. In several of the cases we consider, the optimal level of public effort to prevent hate crime could be greater than or less than the optimal effort for other crime, depending on the complementarity or substitutability between public and private effort. And even for the cases in which the optimal punishment for hate crimes is unambiguously higher than for other crimes, we find important and previously unrecognized implications for policy that encourages or discourages private effort to prevent hate crime.

While this paper has focused on hate crime, the implications of this model extend to any other crimes that have similar effects. One notable example is terrorism, which shares many of the characteristics of hate crime: society puts little weight (or even a negative weight) on the welfare of terrorists, terrorism creates negative externalities (such as fear and the possibility of discrimination against Arab Americans), and private effort to avoid terrorism (for example, by avoiding air travel) is very difficult. Thus, our results should apply equally well to laws that require higher penalties for terrorism or for policies that encourage or discourage private effort to prevent terrorism.

There are several important aspects of this problem that are beyond the scope of our analysis, and thus represent potential directions for future research. First, we have focused only on efficiency issues, and have ignored equity issues. Protected groups are often economically disadvantaged, which could also provide an equity argument for additional protection-though this argument depends on the identity of the victim, whereas hate crime laws are typically based on the motivation for the crime, not the victim's identity.

Second, we have considered the normative issue of optimal hate crime policy, but not the positive political economy issue of why hate crime policy has developed in the way that it has, though the issues are clearly linked. It would be interesting to research the factors that explain states' decisions to enact hate crimes laws.

Third, and perhaps most importantly, further empirical research on the effects of hate crime would be very valuable. The psychology and sociology literatures include 
substantial research on the harm to those who are direct victims of hate crime relative to the harm to victims of other crimes, though this literature is far from conclusive (see McDevitt et al., 2002). And for the other effects modeled in this paper, there exists only anecdotal evidence-though hate-crime experts seem to agree that these effects exist and are important (particularly that hate crime inflicts damage on a broader community than just the direct victim). Empirically measuring these effects would be difficult, but very valuable. 


\section{References}

Ayres, Ian and Steven Levitt, 1998. "Measuring the Positive Externalities from Unobservable Victim Precaution: an Empirical Analysis of Lojack.” Quarterly Journal of Economics 113:43-77.

Becker, Gary, 1968. “Crime and Punishment: an Economic Approach.” Journal of Political Economy 76:169-217.

Ben-Shahar, Omri and Alon Harel, 1995. "Blaming the Victim: Optimal Incentives for Private Precautions Against Crime." Journal of Law, Economics, and Organization 11: 434-455.

Federal Bureau of Investigation, 1991. Hate Crime Statistics Washington, DC

Federal Bureau of Investigation, 2001. Hate Crime Statistics Washington, DC

Freeman, Richard, 1999. "The Economics of Crime.” in: O. Ashenfelter and D. Card, eds., Handbook of Labor Economics. Vol. 3.

Gale, Lewis, Will Heath, and Rand Ressler, 2002. "An Economic Analysis of Hate Crime.” Eastern Economic Journal 28:203-216.

Glaeser, Edward, 2002. "The Political Economy of Hatred.” NBER working paper 9171.

Glaeser, Edward and Bruce Sacerdote, 2003. "Sentencing in Homicide Cases and the Role of Vengeance." Journal of Legal Studies32:362-383.

Grattet, Ryken and Valerie Jenness, 2001. "The Birth and Maturation of Hate Crime Policy in the United States." American Behavioral Scientist, 45:668-696.

Iganski, Paul, 2001. "Hate Crimes Hurt More." American Behavioral Scientist 45:626638.

Jacobs, James and Kimberly Potter, 1998. Hate Crimes: Criminal Law and Identity Politics. Oxford University Press.

Jefferson, Philip and Frederic Pryor, 1999. “On the Geography of Hate.” Economics Letters65:389-395.

Johnson, Stephen and Bryan Byers, 2003. "Attitudes Toward Hate Crime Laws." Journal of Criminal Justice 31:227-235. 
McDevitt, Jack, Jennifer Balboni, Luis Garcia, and Joann Gu, 2001. "Consequences for Victims: A Comparison of Bias- and Non-Bias-Motivated Assaults." American Behavioral Scientist 45:697-713.

McDevitt, Jack, Jack Levin, and Susan Bennett, 2002. "Hate Crime Offenders: An Expanded Typology.” Journal of Social Issues 58:303-317.

Medoff, Marshall, 1999. "Allocation of Time and Hateful Behavior: A Theoretical Analysis of Hate and Hate Crimes." American Journal of Economics and Sociology 58:959-973.

Philipson, Tomas and Richard Posner, 1997. "The Economic Epidemiology of Crime." Journal of Law and Economics.

U. S. Department of Justice, Bureau of Justice Assistance, 1997. A Policymaker's Guide to Hate Crimes. Washington, DC. 


\section{Appendix: Proofs of Results 4 and 5}

\section{Proof of Result 4:}

Let the marginal cost of avoidance effort be $C_{1}^{V}+\varepsilon$. First, we rewrite Condition (2) to find the new level of individual effort:

$$
\Delta U \frac{N^{C}}{N^{V}} P_{1}\left(a^{*}, g\right)-C_{1}^{V}\left(a^{*}\right)-\varepsilon=0 .
$$

Thus, the partial derivative of $a(g, \varepsilon)$ with respect to $\varepsilon$ is given by

$$
a_{2}(g, \varepsilon)=\left[P_{11} \Delta U \frac{N^{C}}{N^{V}}-C_{11}^{V}\right]^{-1}
$$

where the arguments are suppressed for clarity. Note that $a_{2}(g, \varepsilon)$ is strictly negative.

Similarly, we rewrite Condition (5a) to get the first-order condition for the optimal government effort level $g^{*}(\varepsilon)$ :

$$
N^{C}\left[P_{2}+a_{1} P_{1}\right]\{\Delta U-1+P\}-N^{V} a_{1}\left(C_{1}^{V}+\varepsilon\right)-C_{1}^{G}=0 .
$$

Note that $a_{1}(g, \varepsilon)$ is still given by Expression (3), and that it does not vary with $a, g$, or $\varepsilon$. The effect of a marginal increase in $\varepsilon$ on the left-hand side of Condition A2 is given by

$$
\begin{aligned}
& \left.N^{C}\left[\{\Delta U-1+P\}\left(P_{12}+a_{1} P_{11}\right)+\left(P_{2}+a_{1} P_{1}\right) P_{1}\right] a_{2}(g, \varepsilon)-N^{V} a_{1} \mid C_{11}^{V} a_{2}(g, \varepsilon)+1\right] \\
& =N^{C}\left[\{\Delta U-1+P\}\left(P_{12}+a_{1} P_{11}\right)+\left(P_{2}+a_{1} P_{1}\right) P_{1}-a_{1} P_{11} \Delta U\right] a_{2}(g, \varepsilon) \\
& =N^{C}\left[\{\Delta U-1+P\} P_{12} C_{11}^{V}\left(C_{11}^{V}-P_{11} \Delta U \frac{N^{C}}{N^{V}}\right)^{-1}+\left(P_{2}+a_{1} P_{1}\right) P_{1}-a_{1} P_{11} \Delta U \oiint_{2}(g, \varepsilon) .\right.
\end{aligned}
$$

If $P_{12}>0$, then $a_{1}>0$, and each of the three terms in the square brackets in Expression (A3) is greater than zero. Since $a_{2}(g, \varepsilon)$ is strictly negative, then, the value of Expression (A3) is negative, so an increase in $\varepsilon$ lowers the value of Condition (A2) below zero. To 
restore equality, $g$ must fall.

$$
\begin{aligned}
& \text { If } P_{12}=0 \text {, then Expression (A3) reduces to } \\
& N^{C}\left[P_{1} P_{2}\right] a_{2}(g, \varepsilon),
\end{aligned}
$$

which is still strictly negative. Since the square-bracketed term in Expression (A3) is increasing without bound in $P_{12}$, for low enough values of $P_{12}$ Expression (A3) is positive. In that case, an increase in $\varepsilon$ implies that $g$ must rise.

Thus, if government punishment effort and victims' avoidance effort are strong enough substitutes in raising the expected cost of committing a crime, then an increase in the marginal cost of victims' effort leads to a increase in the optimal level of government effort. Otherwise, it leads to a decrease.

\section{Proof of Result 5:}

Let $a_{1 N}\left(g, N^{V}\right)$ denote the partial derivative of $a_{1}\left(g, N^{V}\right)$ with respect to $N^{V}$. Implicit differentiation of Condition (3) yields

$$
a_{1 N}\left(g, N^{V}\right)=\frac{P_{12}\left[-C_{11}^{V} \frac{N^{C}}{\left(N^{V}\right)^{2}} \Delta U\right]}{\left[C_{11}^{V}(a(g))-P_{11}(a(g), g) \frac{N^{C}}{N^{V}} \Delta U\right]^{2}} .
$$

Note that the sign of $a_{1 N}\left(g, N^{V}\right)$ is the opposite of the sign of $P_{12}$. Note also that

$$
N^{V} a_{1 N}+a_{1}=\frac{P_{12}\left[-C_{11}^{V}\left(\frac{N^{C}}{N^{V}} \Delta U\right)^{2} P_{11}\right]}{\left[C_{11}^{V}(a(g))-P_{11}(a(g), g) \frac{N^{C}}{N^{V}} \Delta U\right]^{2}},
$$

which has the same sign as $P_{12}$.

The marginal effect of an increase in $N^{V}$ on the left-hand side of Condition (5a) is given by 


$$
\begin{aligned}
& a_{1 N}\left[N^{C} P_{1}(\Delta U-1+P)-N^{V} C_{1}^{V}\right]-C_{1}^{V} a_{1} \\
& =a_{1 N}\left[N^{C} P_{1}(\Delta U-1+P)\right]-\left[C_{1}^{V}\right]\left(N^{V} a_{1 N}+a_{1}\right) .
\end{aligned}
$$

In Expression (A4), both of the terms in square brackets are positive. If $P_{12}>0$, then $a_{1 N}<0$ and $N^{V} a_{1 N}+a_{1 N}>0$, so the value of Expression (A4) is negative. Thus, an increase in $N^{V}$ lowers the left-hand side of Condition (5a) below zero, and government effort $g$ must fall to restore equality. Analogously, if $P_{12}<0$, then an increase in increase in $N^{V}$ implies a rise in $g$. 